\title{
The impact of diabetes on tuberculosis treatment outcomes: A systematic review
}

\author{
Meghan A Baker ${ }^{1,2}$, Anthony D Harries ${ }^{3,4}$, Christie Y Jeon ${ }^{5,10}$, Jessica E Hart ${ }^{6}$, Anil Kapur ${ }^{7}$, Knut Lönnroth ${ }^{8}$, \\ Salah-Eddine Ottmani ${ }^{8}$, Sunali D Goonesekera ${ }^{2}$ and Megan B Murray ${ }^{2,9^{*}}$
}

\begin{abstract}
Background: Multiple studies of tuberculosis treatment have indicated that patients with diabetes mellitus may experience poor outcomes.

We performed a systematic review and meta-analysis to quantitatively summarize evidence for the impact of diabetes on tuberculosis outcomes.

Methods: We searched PubMed, EMBASE and the World Health Organization Regional Indexes from 1 January 1980 to 31 December 2010 and references of relevant articles for reports of observational studies that included people with diabetes treated for tuberculosis. We reviewed the full text of 742 papers and included 33 studies of which 9 reported culture conversion at two to three months, 12 reported the combined outcome of failure and death, 23 reported death, 4 reported death adjusted for age and other potential confounding factors, 5 reported relapse, and 4 reported drug resistant recurrent tuberculosis.
\end{abstract}

Results: Diabetes is associated with an increased risk of failure and death during tuberculosis treatment. Patients with diabetes have a risk ratio (RR) for the combined outcome of failure and death of 1.69 (95\% Cl, 1.36 to 2.12). The RR of death during tuberculosis treatment among the 23 unadjusted studies is 1.89 (95\% Cl, 1.52 to 2.36), and this increased to an effect estimate of 4.95 ( $95 \% \mathrm{Cl}, 2.69$ to 9.10) among the 4 studies that adjusted for age and other potential confounding factors. Diabetes is also associated with an increased risk of relapse (RR, 3.89; $95 \% \mathrm{Cl}$, 2.43 to 6.23 ). We did not find evidence for an increased risk of tuberculosis recurrence with drug resistant strains among people with diabetes. The studies assessing sputum culture conversion after two to three months of tuberculosis therapy were heterogeneous with relative risks that ranged from 0.79 to 3.25 .

Conclusions: Diabetes increases the risk of failure and death combined, death, and relapse among patients with tuberculosis. This study highlights a need for increased attention to treatment of tuberculosis in people with diabetes, which may include testing for suspected diabetes, improved glucose control, and increased clinical and therapeutic monitoring.

\section{Background}

Tuberculosis (TB) remains a major source of morbidity and mortality throughout the world; one-third of the world's population is estimated to be infected with Mycobacterium tuberculosis, approximately nine million people develop the disease each year, and almost two million die annually from the disease [1,2]. Epidemiological studies have elucidated an association between diabetes mellitus (DM) and the development of TB disease

\footnotetext{
* Correspondence: mmurray@hsph.harvard.edu

2Department of Epidemiology, Harvard School of Public Health, Boston, MA, USA

Full list of author information is available at the end of the article
}

[3-7]. According to a recent systematic review, among cohort studies, people with DM had approximately three times the risk of developing TB disease as people without [4]. The global burden of DM is rising; the prevalence is estimated to reach 438 million by 2030 , and more than $80 \%$ of the adult cases will be in newly developed or developing countries [8]. The convergence of these two epidemics may lead to an increased incidence of TB disease, especially in low and middle income countries with increasing numbers of people with DM and prevalent TB disease [5,9]. For example, in areas such as the border population of South Texas and
C Biomed Central

(c) 2011 Baker et al; licensee BioMed Central Ltd. This is an Open Access article distributed under the terms of the Creative Commons Attribution License (http://creativecommons.org/licenses/by/2.0), which permits unrestricted use, distribution, and reproduction in any medium, provided the original work is properly cited. 
Mexico with a high prevalence of DM, self-reported DM is the most common risk factor associated with TB [10].

Among patients afflicted with both TB and DM, diabetes is reported to be associated with poor TB treatment outcomes $[7,11,12]$; however, a systematic analysis to both clarify and quantify the association between DM and TB outcomes, including persistence of sputum culture positivity, failure, death and relapse, has not been performed. Given the increasing burden of TB patients with DM globally, an association between DM and TB outcomes would suggest that diabetes could increase the number of persons infected by a source case and the number of patients needing anti-TB retreatment regimens. Further clarification and quantification of the association between DM and these outcomes will inform public health measures, and we conducted a systematic review and meta-analysis to this end.

\section{Methods}

We conducted this study according to the Meta-analysis of Observational Studies in Epidemiology (MOOSE) guidelines [13].

\section{Data sources and searches}

We searched the PubMed via the NCBI Entrez system http://www.ncbi.nlm.nih.gov/entrez/query.fcgi, the EMBASE via Ovid http://www.ovid.com, and the World Health Organization Regional Indexes (AIM (AFRO), LILACS (AMRO/PAHO), IMEMR (EMRO), IMSEAR (SEARO), WPRIM (WPRO)) http://www.globalhealthlibrary.net/php/index.php from 1 January 1980 to 31 December 2010 for studies of the association between DM and TB disease outcomes. We also searched bibliographies of identified reports for additional references. Our search strategy is defined in Panel 1.

Panel 1. Search strategy for studies on the association between DM and TB outcomes

\section{PubMed:}

MeSH Terms:

1. Tuberculosis

2. "Diabetes mellitus"

Text Terms:

3. Outcome(s) OR Treatment(s)

4. Risk factor(s)

5. Tuberculosis

6. "Diabetes mellitus"

Search Strings (all inclusive)
a) 1 AND 2
b) 1 AND 3 AND 4
c) 5 AND 6 (for the year preceding 12/10 in which articles may not have been assigned $\mathrm{MeSH}$ terms)

EMBASE and World Health Organization Regional Indexes:
1. Tuberculosis, major subject

2. "Diabetes mellitus"

3. Outcome(s) OR Treatment(s)

4. Risk factor(s)

Search Strings (all inclusive)

a) 1 AND 2

b) 1 AND 3 AND 4

\section{Study selection}

We included studies regardless of language. We compared sources to exclude duplicate references and contacted authors for data that were not available in publications and abstracts. Studies were included if they met the following criteria: 1) They were peer-reviewed reports of studies involving human participants receiving pharmacologic anti-mycobacterial treatment for TB disease. 2) They provided or permitted the computation of an effect estimate of the relationship between DM and at least one of the following five TB treatment outcomes: proportion of treated patients who experienced culture conversion at two to three months, the combined outcome of treatment failure and death, death, relapse, or recurrence with drug-resistant (DR) TB. Treatment failure was defined as sputum smear or culture positivity at five months or later during treatment $[14,15]$. We combined failure and death into a single endpoint that represents poor outcomes. Death was defined as death for any reason during the course of treatment [14-16]. Relapse was defined as bacteriologically positive TB disease that occurred after a patient was considered to have completed treatment or to have been cured [14-16]. Recurrence was defined as TB disease that occurred in a patient with a history of prior treatment for TB. 3) They defined DM as any of the following: baseline diagnosis by self-report, medical records, fasting blood glucose $(\mathrm{FBG}) \geq 126 \mathrm{mg} / \mathrm{dL}$ or $\geq$ $140 \mathrm{mg} / \mathrm{dL}$ (to reflect the present and past American Diabetes Association Guidelines and World Health Organization (WHO) recommendations for the diagnosis of DM $[17,18])$, non-FBG $\geq 200 \mathrm{mg} / \mathrm{dL}$, or treatment with oral hypoglycemic medications or insulin.

We excluded the following: citations without abstracts; anonymous reports; duplicate studies; case reports or studies which did not compare outcomes among people with DM to people without DM; reviews; studies that did not report outcomes in adults; studies that examined the reverse association of the impact of $\mathrm{TB}$ disease on DM or diagnosed DM during TB treatment; studies where the majority of treatment took place prior to 1980 , in order to incorporate short course chemotherapy and assess consistent TB treatment regimens [15]; studies after 1995 that did not adjust for human immunodeficiency virus (HIV) status if study participants 
came from countries with a prevalence of HIV among adults (15 to 49 years) of > 5\%; studies that did not report at least one of the TB outcomes listed above; studies that did not follow patients for the duration of $\mathrm{TB}$ treatment for the outcome of failure and death; studies that assessed the risk of relapse that did not follow patients from the first episode of TB; studies in which people with DM received different anti-TB treatment regimens than people without DM; and studies that either did not provide effect estimates in odds ratios (ORs), rate ratios, hazard ratios (HRs), or RRs or did not allow for the computation of these values.

\section{Data extraction and quality assessment}

For every study that met our eligibility criteria, two investigators $(\mathrm{MB}$ and $\mathrm{JH}$ or $\mathrm{CJ})$ independently collected detailed information on the year, country, study design, study population, type of TB outcome, diagnosis of DM and TB, adjustment for age, HIV and other potential confounders, proportion of treated patients who experienced the outcomes of interest, effect sizes, and 95\% confidence intervals. Differences were resolved by discussion and consensus. For non-English language papers, bilingual translators trained in medicine or public health helped classify studies and extract data with $\mathrm{MB}$ and $\mathrm{JH}$.

TB death and relapse are relatively rare events; therefore, we assumed that ORs, RRs, and HRs provided a similar risk estimate, and we reported them as a common effect estimate in the death and relapse analyses [19].

\section{Data synthesis and analysis}

We performed separate analyses for each of the outcomes and assessed heterogeneity of effect estimates using the Cochran Q test for heterogeneity and the $\mathrm{I}^{2}$ statistic described by Higgins et al. [20,21]. The 95\% confidence intervals (CIs) for the $\mathrm{I}^{2}$ were calculated using the test-based methods [21]. We performed metaanalysis to compute a summary estimate only for those studies that did not show significant heterogeneity, defined as $\mathrm{I}^{2}<50 \%$ [21]. We decided $a$ priori to use the random effects model and weighting method according to the method described by DerSimonian and Laird [22] as we expected the true effect of DM on TB outcomes to vary and because it would yield conservative 95\% CIs.

We addressed potential causes of heterogeneity and the impact of study quality for the outcome analyses with an $\mathrm{I}^{2}>10 \%$. We compared pooled effect estimates for subgroups categorized by background TB incidence and pulmonary versus other types of TB, and by the following quality-associated variables: time of assessment of DM in relation to TB diagnosis, exposure classification (self-report, medical records and DM medications versus laboratory tests), loss to follow-up, and the use of survival analysis. We considered studies to be of higher quality if they specified that patients were diagnosed with DM prior to TB diagnosis, if DM was diagnosed based on medical records, self-report or use of DM medications (blood glucose measurements at the time of TB diagnosis may overestimate DM, as TB disease is associated with increased blood glucose levels [23,24]), if studies adjusted for at least age, if they reported loss to follow-up through default and transfer out of less than $10 \%$ of the cohort, and if they estimated a HR using survival analysis. We regressed study-specific log-transformed RRs by the variables representing the study characteristics, weighting the studies by the inverse of the sum of within-study and between-study variance for all studies within the comparison. Coefficients of metaregression represent differences in log-transformed RRs between the subgroups. We tested the significance of these coefficients by Student's $t$-test, and the significance was set at $P<0.05$. We performed a separate analysis for studies assessing the outcome of death that adjusted for age and other confounding factors.

We assessed publication bias using Begg's and Egger's tests $[25,26]$ and by visual inspection for asymmetry of a plot of the natural logarithms of the effect estimates against the standard errors [25]. Statistical procedures were performed using STATA version 10, Texas [27].

\section{Results}

We identified and screened 3,623 papers by titles and abstracts, including 2,841 papers in English and 782 papers in other languages. We excluded 2,881 papers, because they did not study TB outcomes, studied exclusively surgical interventions, lacked a comparison group, were studies conducted exclusively among children, were published before 1980, lacked an abstract, or were case reports, reviews, or anonymous reports (Figure 1). The full texts of the remaining 742 papers were analyzed and on the basis of that review, we excluded 709 articles because they did not present an effect estimate or provide data from which an effect estimate could be calculated (142), they did not assess DM (378), they did not assess the TB outcomes defined in the methods (74), they lacked a comparison group without DM (49), they grouped DM with other chronic diseases (26), the treatment regimen differed between the population with DM and without DM (5), they were reviews, case reports, or duplicate studies (24), the majority of treatment took place before 1980 (6), they did not follow patients from the first episode of TB for the outcome of relapse (3), or they measured the reverse association between DM and TB or diagnosed DM after TB diagnosis (2). No studies conducted in countries with a high prevalence of HIV were excluded on the basis of not 


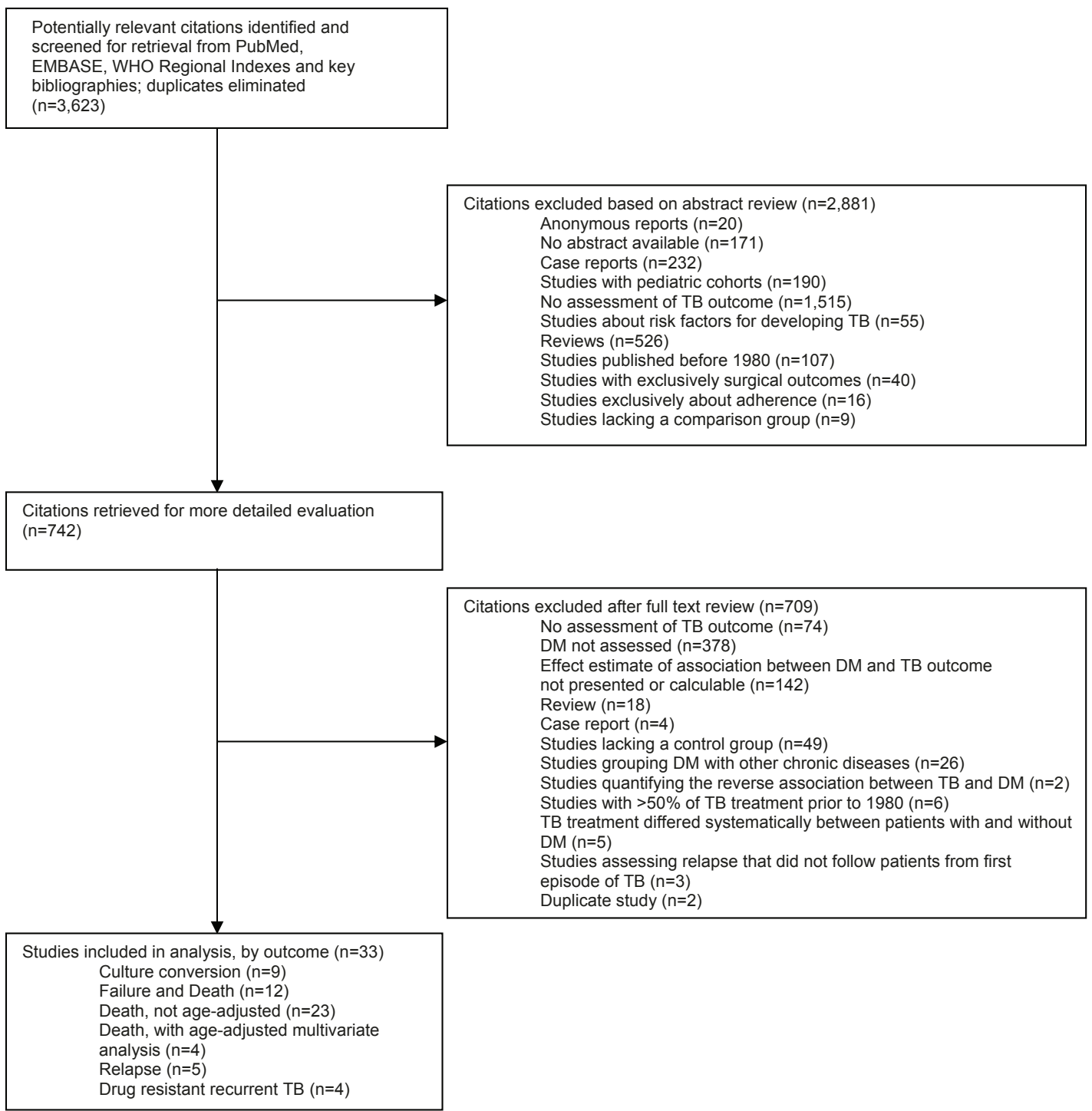

Figure 1 The literature search for studies on the association between DM and TB outcomes.

adjusting for HIV status. We contacted 21 authors for further information and clarification and obtained additional data from 7 of these. We included 33 studies of which 9 reported culture conversion at two to three months, 12 reported the combined outcome of failure and death, 23 reported death, 4 reported death adjusted for age and other potential confounding factors, 5 reported relapse, and 4 reported recurrence with drug resistant tuberculosis (Table 1) [3,11,12,28-57]. The included studies were written in English (25), Japanese (4), French (2), and Spanish (2).

\section{Sputum culture conversion at two to three months}

We found substantial heterogeneity of effect estimates among the nine studies that assessed the risk of remaining sputum culture positive after two to three months of anti-TB therapy comparing patients with and without DM (Figure 2). Relative risks ranged from 0.79 to 3.25 , and between-study variance accounted for $58 \%$ of the total variance among studies. Because of this heterogeneity, we do not report a summary estimate. We found no evidence for publication bias by either Begg's test $(P=0.30)$ or Egger's test $(P=0.27)$ (Additional file 1). Among the three studies that reported RRs of $<1$ for the risk of sputum culture positivity at two to three months, one reported a significant difference in sputum culture conversion at six months (unadjusted OR 2.69 (95\% CI, 1.01 to 7.14), adjusted OR 7.65 (95\% CI, 1.89 to 30.95)) [11], while another found a trend toward increased time to 
Table 1 Characteristics of included studies for the association between DM and TB outcomes

\begin{tabular}{|c|c|c|c|c|c|c|c|c|c|c|c|c|}
\hline \multirow[b]{2}{*}{ Study } & \multirow[b]{2}{*}{ Type of study } & \multirow[b]{2}{*}{ Country } & \multirow[b]{2}{*}{ Type of TB } & \multirow[b]{2}{*}{$\begin{array}{c}\text { Total } \\
\mathrm{n}\end{array}$} & \multirow[b]{2}{*}{$\begin{array}{l}\text { Population } \\
\text { with DM } \\
\mathrm{n}\end{array}$} & \multicolumn{6}{|c|}{ Outcomes } & \multirow[b]{2}{*}{ DM Definition } \\
\hline & & & & & & $\begin{array}{c}\text { Sputum } \\
\text { Culture } \\
\text { Conversion } \\
2-3 \\
\text { months }\end{array}$ & $\begin{array}{l}\text { Failure } \\
\text { And } \\
\text { Death }\end{array}$ & Death & $\begin{array}{c}\text { Adjusted } \\
\text { Variables for } \\
\text { Death Outcome }\end{array}$ & Relapse & $\begin{array}{c}\text { DR } \\
\text { Recurrence }\end{array}$ & \\
\hline $\begin{array}{l}\text { Alisjahbana } \\
{[11]}\end{array}$ & Prospective cohort & Indonesia & Pulmonary TB & 634 & 94 & $\sqrt{ }$ & $\sqrt{ }$ & $\sqrt{ }$ & & & & $\begin{array}{l}2 \text { measurements of FBG }>126 \\
\mathrm{mg} / \mathrm{dL}\end{array}$ \\
\hline $\begin{array}{l}\text { Ambrosetti } \\
{[28]}\end{array}$ & Prospective cohort & Italy & $\begin{array}{l}\text { Undifferentiated } \\
\text { TB }\end{array}$ & 778 & 32 & & $\sqrt{ }$ & $\sqrt{ }$ & & & & Medical records \\
\hline $\begin{array}{l}\text { Ambrosetti } \\
\text { [29] }\end{array}$ & Prospective cohort & Italy & $\begin{array}{l}\text { Undifferentiated } \\
\text { TB }\end{array}$ & 838 & 50 & & $\sqrt{ }$ & $\sqrt{ }$ & & & & Medical records \\
\hline $\begin{array}{l}\text { Ambrosetti } \\
\text { [30] }\end{array}$ & Prospective cohort & Italy & $\begin{array}{l}\text { Undifferentiated } \\
\text { TB }\end{array}$ & 715 & 40 & & $\sqrt{ }$ & $\sqrt{ }$ & & & & Medical records \\
\hline $\begin{array}{l}\text { Anunnatsiri } \\
{[31]}\end{array}$ & Retrospective cohort & Thailand & Pulmonary TB & 226 & 117 & & $\sqrt{ }$ & & & & & Medical records \\
\hline $\begin{array}{l}\text { Banu Rekha } \\
\text { [32] }\end{array}$ & $\begin{array}{l}\text { Retrospective } \\
\text { analysis of } 3 \\
\text { concurrent studies }\end{array}$ & India & Pulmonary TB & 190 & 92 & $\sqrt{ }$ & & & & & & Medical records, FBG \\
\hline Bashar [33] & $\begin{array}{l}\text { Retrospective case- } \\
\text { control }\end{array}$ & USA & $\begin{array}{l}\text { Undifferentiated } \\
\text { TB }\end{array}$ & 155 & 50 & & & $\sqrt{ }$ & & & & Medical records \\
\hline Blanco [34] & Retrospective cohort & $\begin{array}{l}\text { Canary } \\
\text { Islands, } \\
\text { Spain }\end{array}$ & Pulmonary TB & 98 & 14 & $\sqrt{ }$ & & & & & & Medical records \\
\hline Centis [35] & Prospective cohort & Italy & $\begin{array}{l}\text { Undifferentiated } \\
\text { TB }\end{array}$ & 1,162 & 56 & & $\sqrt{ }$ & $\sqrt{ }$ & & & & Medical records \\
\hline Centis [36] & Prospective cohort & Italy & $\begin{array}{l}\text { Undifferentiated } \\
\text { TB }\end{array}$ & 906 & 40 & & $\sqrt{ }$ & $\sqrt{ }$ & & & & Medical records \\
\hline Chiang [37] & Retrospective cohort & Taiwan & Pulmonary TB & 1,127 & 241 & & $\sqrt{ }$ & $\sqrt{ }$ & & & & Medical records \\
\hline Dooley [12] & Retrospective cohort & USA & $\begin{array}{l}\text { Undifferentiated } \\
\text { TB }\end{array}$ & 297 & 42 & $\sqrt{ }$ & & $\sqrt{ }$ & $\begin{array}{l}\text { Age, HIV, weight, } \\
\text { foreign birth }\end{array}$ & & & $\begin{array}{l}\text { Medical records, } \\
\text { non-FBG > } 200 \mathrm{mg} / \mathrm{dL} \text {, } \\
\text { DM medications }\end{array}$ \\
\hline Fielder [38] & Retrospective cohort & USA & Pulmonary TB & 174 & 22 & & & $\sqrt{ }$ & Age & & & Medical records \\
\hline $\begin{array}{l}\text { Fisher-Hoch } \\
\text { [39] }\end{array}$ & Retrospective cohort & $\begin{array}{l}\text { Mexico \& } \\
\text { USA }\end{array}$ & $\begin{array}{l}\text { Undifferentiated } \\
\text { TB }\end{array}$ & 2,878 & 688 & & & $\sqrt{ }$ & & & $\sqrt{ }$ & Self report \\
\hline Guler [40] & Retrospective cohort & Turkey & Pulmonary TB & 306 & 44 & $\sqrt{ }$ & & & & & & Medical records \\
\hline Hara [41] & Retrospective cohort & Japan & Pulmonary TB & 624 & 112 & $\sqrt{ }$ & & & & & & Medical records \\
\hline Hasibi [42] & Retrospective cohort & Iran & Disseminated TB & 50 & 6 & & & $\sqrt{ }$ & & & & Medical records \\
\hline Ito [43] & Retrospective cohort & Japan & $\begin{array}{l}\text { Undifferentiated } \\
\text { TB }\end{array}$ & 109 & 16 & & & & & & $\sqrt{ }$ & Medical records \\
\hline $\begin{array}{l}\text { Kitahara } \\
{[44]}\end{array}$ & Retrospective cohort & Japan & Pulmonary TB & 520 & 71 & $\sqrt{ }$ & & $\sqrt{ }$ & & & & Medical records \\
\hline $\begin{array}{l}\text { Kourbatova } \\
{[45]}\end{array}$ & $\begin{array}{l}\text { Retrospective case- } \\
\text { control }\end{array}$ & Russia & $\begin{array}{l}\text { Undifferentiated } \\
\text { TB }\end{array}$ & 460 & 20 & & & $\sqrt{ }$ & & & & Medical records \\
\hline
\end{tabular}

Kourbatova Retrospective case- Russia Undifferentiated 460 
Table 1 Characteristics of included studies for the association between DM and TB outcomes (Continued)

\begin{tabular}{|c|c|c|c|c|c|c|c|c|c|c|c|c|}
\hline Maalej [46] & $\begin{array}{l}\text { Retrospective case- } \\
\text { control }\end{array}$ & Tunisia & Pulmonary TB & 142 & 60 & & & $\sqrt{ }$ & & $\sqrt{ }$ & & Medical records \\
\hline $\begin{array}{l}\text { Mboussa } \\
{[47]}\end{array}$ & Retrospective cohort & $\begin{array}{l}\text { Republic } \\
\text { of the } \\
\text { Congo }\end{array}$ & Pulmonary TB & 132 & 32 & & $\sqrt{ }$ & $\sqrt{ }$ & & $\sqrt{ }$ & & $\begin{array}{l}2 \text { measurements of } F B G \geq 126 \\
\mathrm{mg} / \mathrm{dL}\end{array}$ \\
\hline Oursler [48] & Retrospective cohort & USA & Pulmonary TB & 139 & 18 & & & $\sqrt{ }$ & $\begin{array}{l}\text { Age, HIV, } \\
\text { renal, COPD }\end{array}$ & & & Medical records \\
\hline Pina [49] & Retrospective cohort & Spain & $\begin{array}{l}\text { Undifferentiated } \\
\text { TB }\end{array}$ & 1,511 & 73 & & & $\sqrt{ }$ & & & & Medical records \\
\hline $\begin{array}{l}\text { Ponce-De- } \\
\text { Leon [3] }\end{array}$ & Prospective cohort & Mexico & Pulmonary TB & 581 & 172 & & $\sqrt{ }$ & $\sqrt{ }$ & & & & $\begin{array}{l}\text { Medical records (FBG } \geq 126 \mathrm{mg} / \\
\mathrm{dL} \text {, non-FBG } \geq 200 \mathrm{mg} / \mathrm{dL} \\
\text { sensitivity analysis) }\end{array}$ \\
\hline Singla [50] & Retrospective cohort & $\begin{array}{l}\text { Saudi } \\
\text { Arabia }\end{array}$ & Pulmonary TB & 692 & 187 & & $\sqrt{ }$ & $\sqrt{ }$ & & $\sqrt{ }$ & & $\begin{array}{l}2 \text { measurements of FBG }>140 \\
\mathrm{mg} / \mathrm{dL}\end{array}$ \\
\hline $\begin{array}{l}\text { Subhash } \\
\text { [51] }\end{array}$ & Retrospective cohort & India & $\begin{array}{l}\text { Undifferentiated } \\
\text { TB }\end{array}$ & 361 & 72 & & & & & & $\sqrt{ }$ & $\begin{array}{l}\text { FBG }>140 \mathrm{mg} / \mathrm{dL} \text {, medical } \\
\text { records and DM medication or } \\
\text { diet }\end{array}$ \\
\hline Tatar [52] & Retrospective cohort & Turkey & $\begin{array}{l}\text { Undifferentiated } \\
\text { TB }\end{array}$ & 156 & 78 & $\sqrt{ }$ & & $\sqrt{ }$ & & & & Medical records \\
\hline $\begin{array}{l}\text { Vasankari } \\
\text { [53] }\end{array}$ & Retrospective cohort & Finland & Pulmonary TB & 629 & 92 & & & $\sqrt{ }$ & & & & Treatment with DM medications \\
\hline Wada [54] & Retrospective cohort & Japan & Pulmonary TB & 726 & 143 & $\sqrt{ }$ & & & & $\sqrt{ }$ & & Medical records \\
\hline Wang [55] & Retrospective cohort & Taiwan & Pulmonary TB & 453 & 75 & & & & & & $\sqrt{ }$ & Medical records \\
\hline Wang [56] & Retrospective cohort & Taiwan & Pulmonary TB & 217 & 74 & & $\sqrt{ }$ & $\sqrt{ }$ & Age, sex & & & $\begin{array}{l}\text { Medical records and DM } \\
\text { medication or FBG }>126 \mathrm{mg} / \mathrm{dL}\end{array}$ \\
\hline Zhang [57] & $\begin{array}{l}\text { Retrospective } \\
\text { Cohort }\end{array}$ & China & Pulmonary TB & 2,141 & 203 & & & & & $\sqrt{ }$ & & $\mathrm{FBG} \geq 126 \mathrm{mg} / \mathrm{dL}$ \\
\hline
\end{tabular}




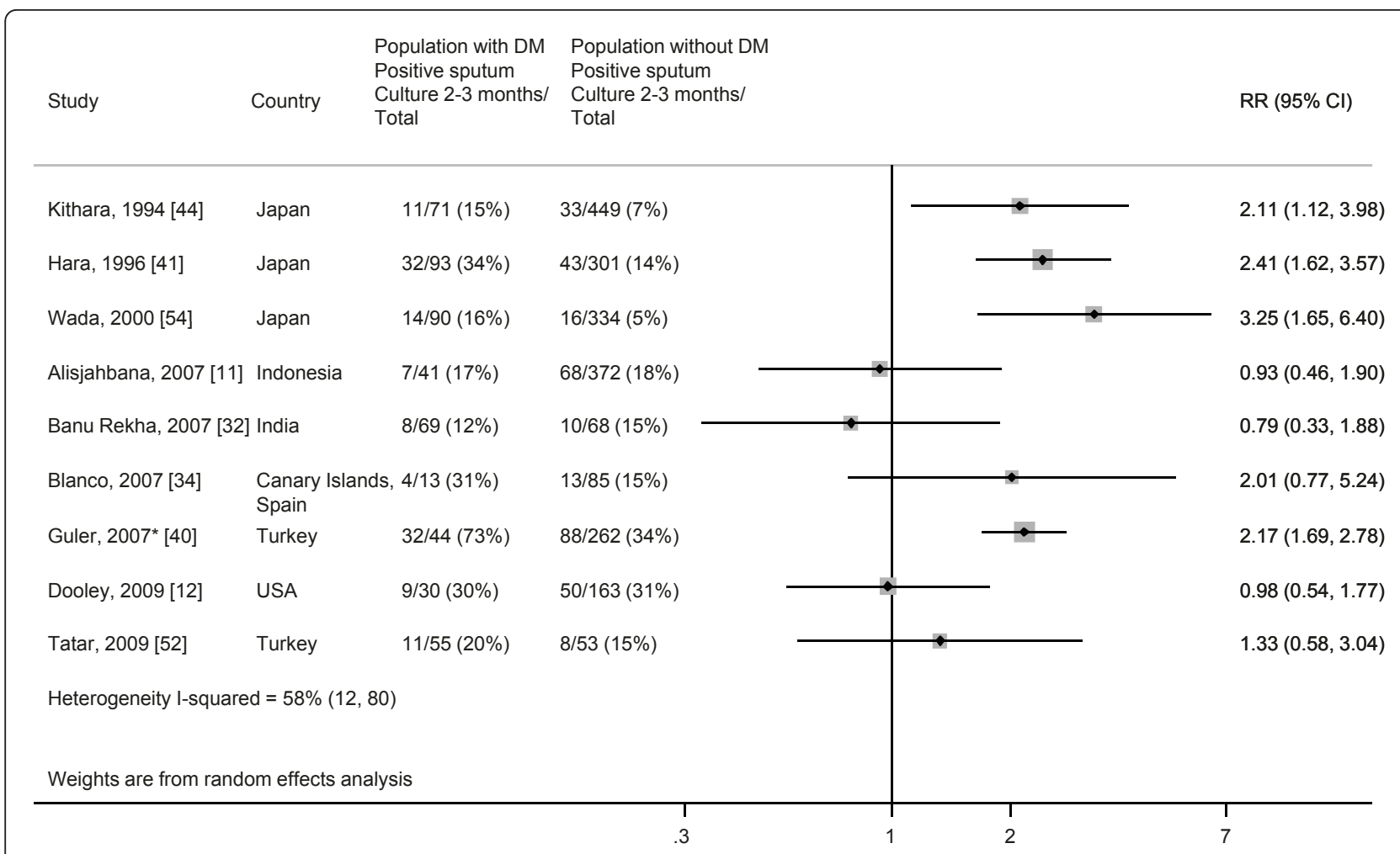

Figure 2 Risk of remaining sputum culture positive for TB patients with DM compared with TB patients without DM. Size of the square is proportional to the precision of the study-specific effect estimates, and the bars indicate the corresponding 95\% Cls. *The RR for Guler et al. [40] was calculated using the $\mathrm{OR}, \mathrm{Cl}$ and total number of patients with and without DM provided in the paper.

sputum culture conversion among patients with diabetes $(P=0.09)[12]$.

The sensitivity analysis presented in Table 2 shows that the estimated risk of remaining sputum culture positive at two to three months was greater in studies that used medical records, patient report and medication history to classify patients with diabetes, rather than laboratory tests conducted at the initiation of treatment (RR 2.22 (95\% CI, 1.85 to 2.66) and RR 0.92 (95\% CI, 0.62 to 1.38 ) respectively) (meta-regression $P<0.01$ ). None of the studies explicitly stated that DM was diagnosed prior to TB.

\section{Failure and death}

The pooled RR of the combined outcome, failure and death, among the 12 studies that included both outcomes was 1.69 (95\% CI, 1.36 to 2.12). Between-study variance accounted for $19 \%$ of the total variance (Figure 3). Although Egger's test suggested publication bias $(P=$ $0.01)$, Begg's test was not significant $(P=0.49)$ (Additional file 2). The sensitivity analysis did not include several of the quality associated strata, because none of the reviewed studies explicitly stated that the DM diagnosis predated the TB diagnosis, and none performed a survival analysis. As shown in Table 2 although some of the variability among the studies is explained by the variables included, substantial heterogeneity remains after the meta-regression.

\section{Death}

Among the 23 studies that compared the risk of death during $\mathrm{TB}$ treatment in patients with $\mathrm{DM}$ versus patients without DM, we found moderate heterogeneity of effect estimates with between study variance accounting for $46 \%$ of the total variance (Figure 4 ). The pooled RR from the random effects analysis was 1.89 (95\% CI, 1.52 to 2.36). Although Egger's test suggested publication bias $(P=0.01)$, Begg's test was not significant $(P=$ $0.19)$ (Additional file 3). The one study that evaluated the effect estimate using survival analysis found a HR of 4.8 (95\% CI, 2.0 to 11.6) [48]. None of the studies explicitly stated that DM was diagnosed prior to TB.

When we restricted the analysis to those four studies which adjusted for age and other potential confounders, we did not find heterogeneity among the effect estimates despite the fact that each study controlled for a different set of confounders. The random effects pooled OR was 4.95 (95\% CI, 2.69 to 9.10) (Figure 5). There was no 
Table 2 Sensitivity analysis to identify sources of heterogeneity in the association between DM and TB

\begin{tabular}{|c|c|c|c|c|c|c|c|c|}
\hline TB Outcome & Variables & $\begin{array}{l}\text { Study Characteristics } \\
\text { (No. of studies) }\end{array}$ & $\begin{array}{l}\text { Summary effect } \\
\text { estimates }\end{array}$ & $95 \% \mathrm{Cl}$ & $\mathrm{I}^{2}$ & $\begin{array}{c}95 \% \mathrm{Cl} \\
\mathrm{I}^{2}\end{array}$ & $\begin{array}{c}\text { P Value } \\
\text { Heterogeneity }\end{array}$ & $\begin{array}{l}\text { P Value } \\
\text { Meta- } \\
\text { regression }\end{array}$ \\
\hline \multirow[t]{9}{*}{$\begin{array}{l}\text { Sputum culture conversion } \\
\text { at 2-3 months }\end{array}$} & $\begin{array}{l}\text { Background TB } \\
\text { incidence }\end{array}$ & $\geq 100,000(2)$ & 0.87 & $0.50-1.51$ & $0 \%$ & NA & 0.77 & 0.53 \\
\hline & & $\begin{array}{l}\geq 10,000 \text { and } \\
<100,000(6)\end{array}$ & 2.22 & $1.85-2.66$ & $0 \%$ & 0\%-75\% & 0.70 & \\
\hline & & $<10,000(1)$ & 0.98 & $0.54-1.77$ & NA & NA & NA & \\
\hline & Type of TB & Pulmonary (7) & 1.91 & $1.41-2.59$ & $52 \%$ & 0\%-79\% & 0.05 & 0.18 \\
\hline & & $\begin{array}{l}\text { Pulmonary and } \\
\text { extrapulmonary (2) }\end{array}$ & 1.08 & $0.67-1.76$ & $0 \%$ & NA & 0.56 & \\
\hline & DM diagnosis & $\begin{array}{l}\text { Patient or medical } \\
\text { report (6) }\end{array}$ & 2.22 & $1.85-2.66$ & $0 \%$ & 0\%-75\% & 0.71 & $<0.01$ \\
\hline & & Laboratory test (3) & 0.92 & $0.62-1.38$ & $0 \%$ & 0\%-90\% & 0.92 & \\
\hline & $\begin{array}{l}\text { Loss to follow- } \\
\text { up }\end{array}$ & $<10 \%(1)$ & 1.33 & $0.58-3.04$ & NA & NA & NA & 0.84 \\
\hline & & $\geq 10 \%(2)$ & 1.75 & $0.51-5.95$ & $84 \%$ & NA & 0.01 & \\
\hline \multirow[t]{9}{*}{ Failure and Death } & $\begin{array}{l}\text { Background TB } \\
\text { incidence }\end{array}$ & $\geq 100,000$ & 2.11 & $1.26-3.53$ & $20 \%$ & 0\%-92\% & 0.29 & 0.63 \\
\hline & & $\begin{array}{l}\geq 10,000 \text { and } \\
<100,000(6)\end{array}$ & 1.49 & $1.23-1.80$ & $0 \%$ & $0 \%-75 \%$ & 0.51 & \\
\hline & & $<10,000(3)$ & 1.80 & $0.63-5.13$ & $55 \%$ & 0\%-87\% & 0.11 & \\
\hline & Type of TB & Pulmonary (7) & 1.62 & $1.26-2.07$ & $26 \%$ & $0 \%-68 \%$ & 0.23 & 0.49 \\
\hline & & $\begin{array}{l}\text { Pulmonary and } \\
\text { extrapulmonary (5) }\end{array}$ & 2.08 & $1.27-3.42$ & $6 \%$ & 0\%-80\% & 0.38 & \\
\hline & DM diagnosis & $\begin{array}{l}\text { Patient or medical } \\
\text { report (8) }\end{array}$ & 1.51 & $1.25-1.82$ & $0 \%$ & $0 \%-68 \%$ & 0.49 & 0.10 \\
\hline & & $\begin{array}{l}\text { Laboratory diagnosis } \\
\text { (4) }\end{array}$ & 1.97 & $1.12-3.46$ & $42 \%$ & 0\%-80\% & 0.16 & \\
\hline & $\begin{array}{l}\text { Loss to follow- } \\
\text { up }\end{array}$ & $<10 \%(4)$ & 1.72 & $1.25-2.37$ & $52 \%$ & 0\%-84\% & 0.10 & 0.98 \\
\hline & & $\geq 10 \%(8)$ & 1.77 & $1.21-2.59$ & $3 \%$ & $0 \%-69 \%$ & 0.41 & \\
\hline \multirow[t]{11}{*}{ Death } & $\begin{array}{l}\text { Background TB } \\
\text { incidence }\end{array}$ & $\geq 100,000(3)$ & 2.63 & $0.86-8.02$ & $62 \%$ & 0\%-89\% & 0.07 & 0.98 \\
\hline & & $\begin{array}{l}\geq 10,000 \text { and } \\
<100,000(13)\end{array}$ & 1.62 & $1.33-1.97$ & $8 \%$ & $0 \%-60 \%$ & 0.37 & \\
\hline & & $<10,000(7)$ & 1.95 & $1.12-3.40$ & $74 \%$ & $45 \%-88 \%$ & $<0.01$ & \\
\hline & Type of TB & Pulmonary (11) & 1.97 & $1.46-2.65$ & $52 \%$ & $5 \%-76 \%$ & 0.02 & 0.59 \\
\hline & & $\begin{array}{l}\text { Pulmonary and } \\
\text { extrapulmonary (12) }\end{array}$ & 1.84 & $1.28-2.64$ & $41 \%$ & 0\%-70\% & 0.07 & \\
\hline & DM diagnosis & $\begin{array}{l}\text { Patient or medical } \\
\text { report (18) }\end{array}$ & 1.82 & $1.42-2.32$ & $50 \%$ & $15 \%-71 \%$ & $<0.01$ & 0.33 \\
\hline & & $\begin{array}{l}\text { Laboratory diagnosis } \\
\text { (5) }\end{array}$ & 2.37 & $1.49-3.78$ & $1 \%$ & 0\%-79\% & 0.40 & \\
\hline & $\begin{array}{l}\text { Loss to follow- } \\
\text { up }\end{array}$ & $<10 \%(9)$ & 1.43 & $1.19-1.72$ & $16 \%$ & $0 \%-58 \%$ & 0.30 & 0.12 \\
\hline & & $\geq 10 \%(7)$ & 2.22 & $1.24-3.98$ & $21 \%$ & $0 \%-64 \%$ & 0.27 & \\
\hline & Survival analysis & Survival analysis (1) & 4.8 & $2.0-11.6$ & NA & NA & NA & 0.18 \\
\hline & & Alternative analysis (22) & 1.81 & $1.45-2.26$ & $42 \%$ & $4 \%-65 \%$ & 0.02 & \\
\hline
\end{tabular}

evidence for publication bias by Begg's test $(P=0.17)$ or Egger's test $(P=0.18)$ (Additional file 4$)$.

\section{Relapse}

Among the five studies that assessed the risk of TB relapse, the random effects pooled RR was 3.89 (95\% CI,
2.43 to 6.23) for relapse after TB cure or treatment completion among patients with DM versus patients without DM (Figure 6). There was no evidence for heterogeneity among the studies that assessed this outcome and no evidence for publication bias by Begg's test $(P=$ $1.00)$ or Egger's test $(P=0.81)$ (Additional file 5). 


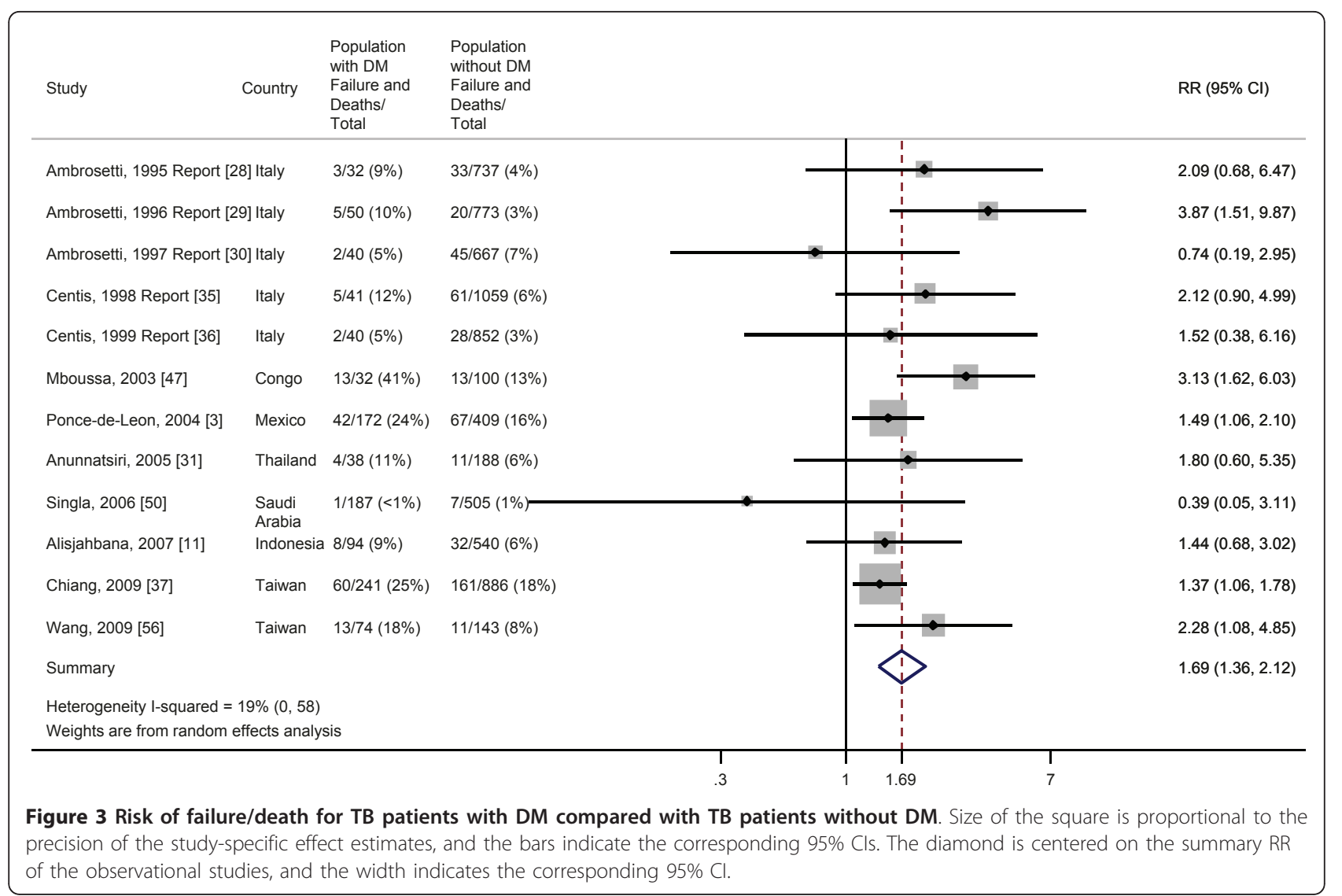

\section{Drug resistant recurrent disease}

The random effects pooled OR was 1.24 (95\% CI, 0.72 to 2.16) for the four studies that assessed the odds of developing recurrent TB that is DR (Figure 7). Studies were not heterogeneous, as between study variance accounted for $6 \%$ of the total variance among the studies included in this analysis. We did not find evidence for publication bias by Begg's test $(P=0.62)$ or Egger's test $(P=0.76)$ (Additional file 6$)$.

\section{Discussion}

This systematic review of the impact of DM on outcomes of TB treatment determines that DM increases the risk of the combined outcome of failure and death, death, and relapse. Notably, the pooled effect estimate for death among studies that adjusted for age and other confounding factors was found to be higher than the pooled effect estimate among the unadjusted studies. This finding not only suggests that patients with DM receiving TB therapy are at risk for poor outcomes, but that outcome studies that do not control for appropriate confounders may underestimate the negative impact of DM in TB patients. Future studies of the impact of DM on TB outcomes should be designed to minimize the potential bias due to confounding factors such as age and HIV.
The results of the studies analyzing culture positivity at two to three months after initiation of TB treatment were heterogeneous with five of the nine studies reporting an RR of greater than two and three reporting an RR of less than one. Two of those three papers reported delay in sputum culture conversion in persons with DM at some point during the course of treatment $[11,12]$. Thus, all but one of the papers included in this analysis reported delay in sputum culture conversion, although this outcome occurred at different times.

The effect of DM on both the combined outcome of failure and death and death alone in studies that did not adjust for age and other confounding factors was relatively modest; however, the effect on death not only persisted, but increased among those studies that adjusted for potential confounders. An explanation for the higher risk observed in the studies that adjusted for confounding factors may be that patients who die during TB treatment have other strong risk factors for death such as HIV or co-morbidities that tend to reduce the apparent impact of DM in the unadjusted analyses. However, because the studies that adjusted for confounders were all performed in industrialized countries where TB mortality rates tend to be high [58], it is difficult to generalize these results to higher burden settings. 


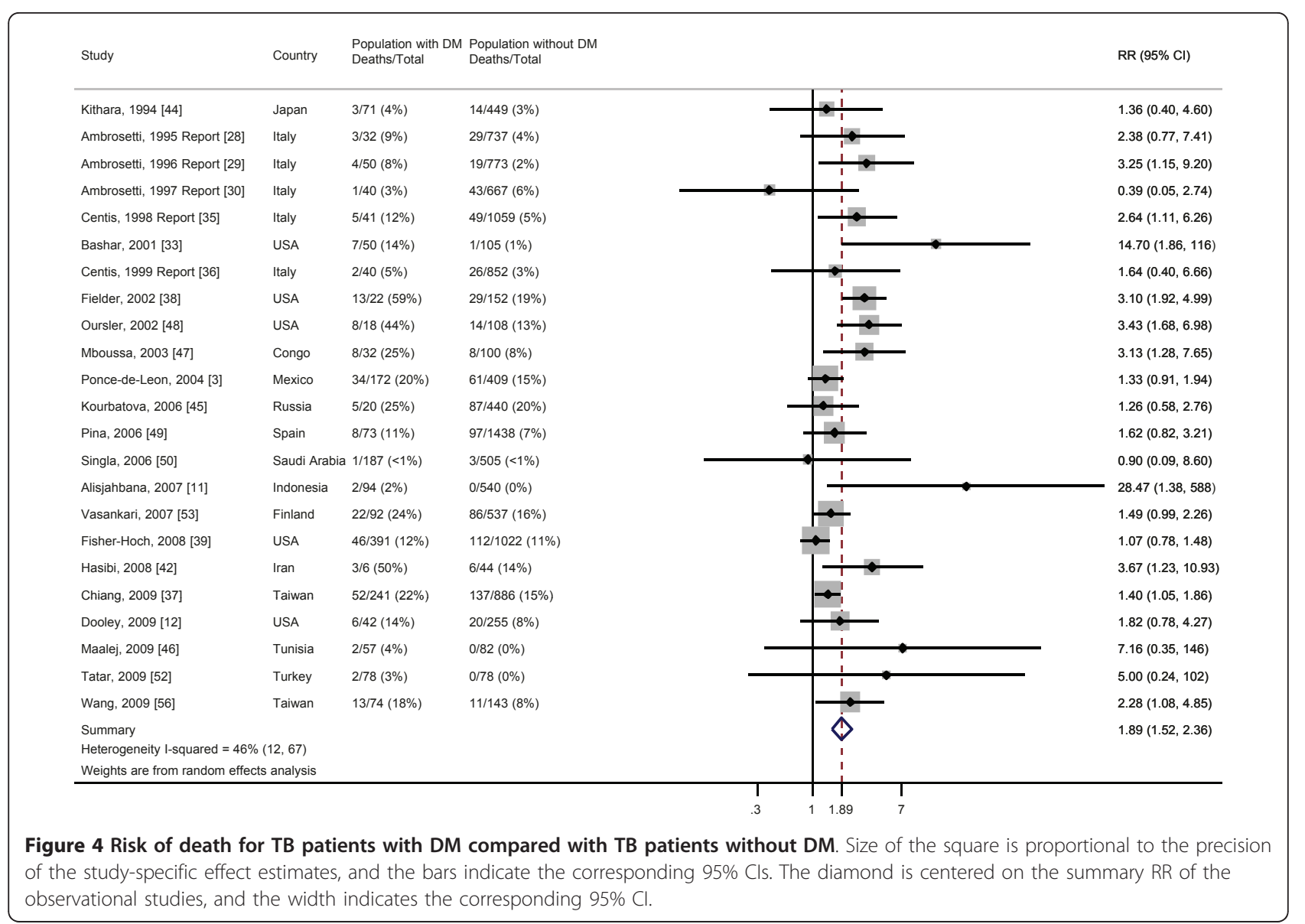

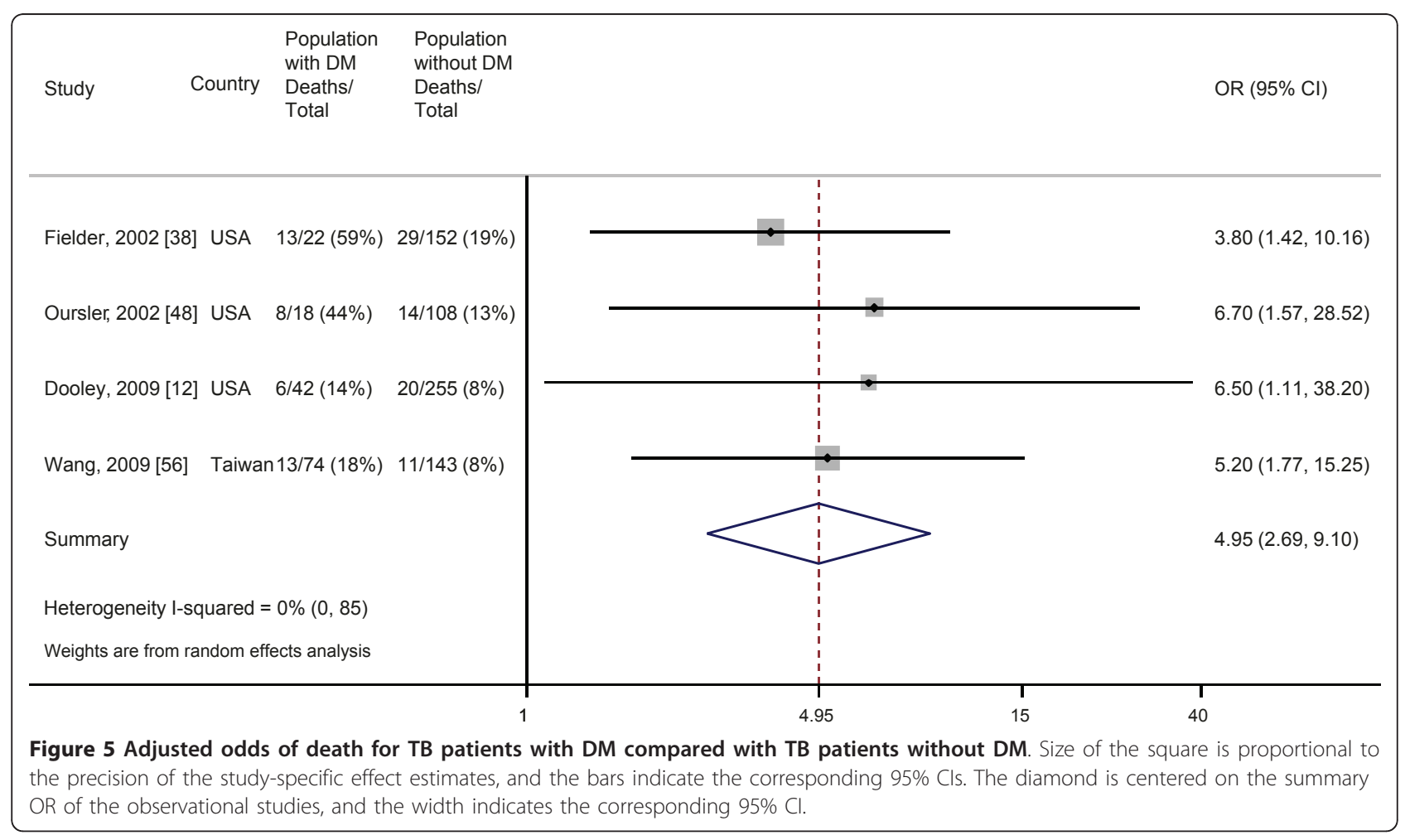




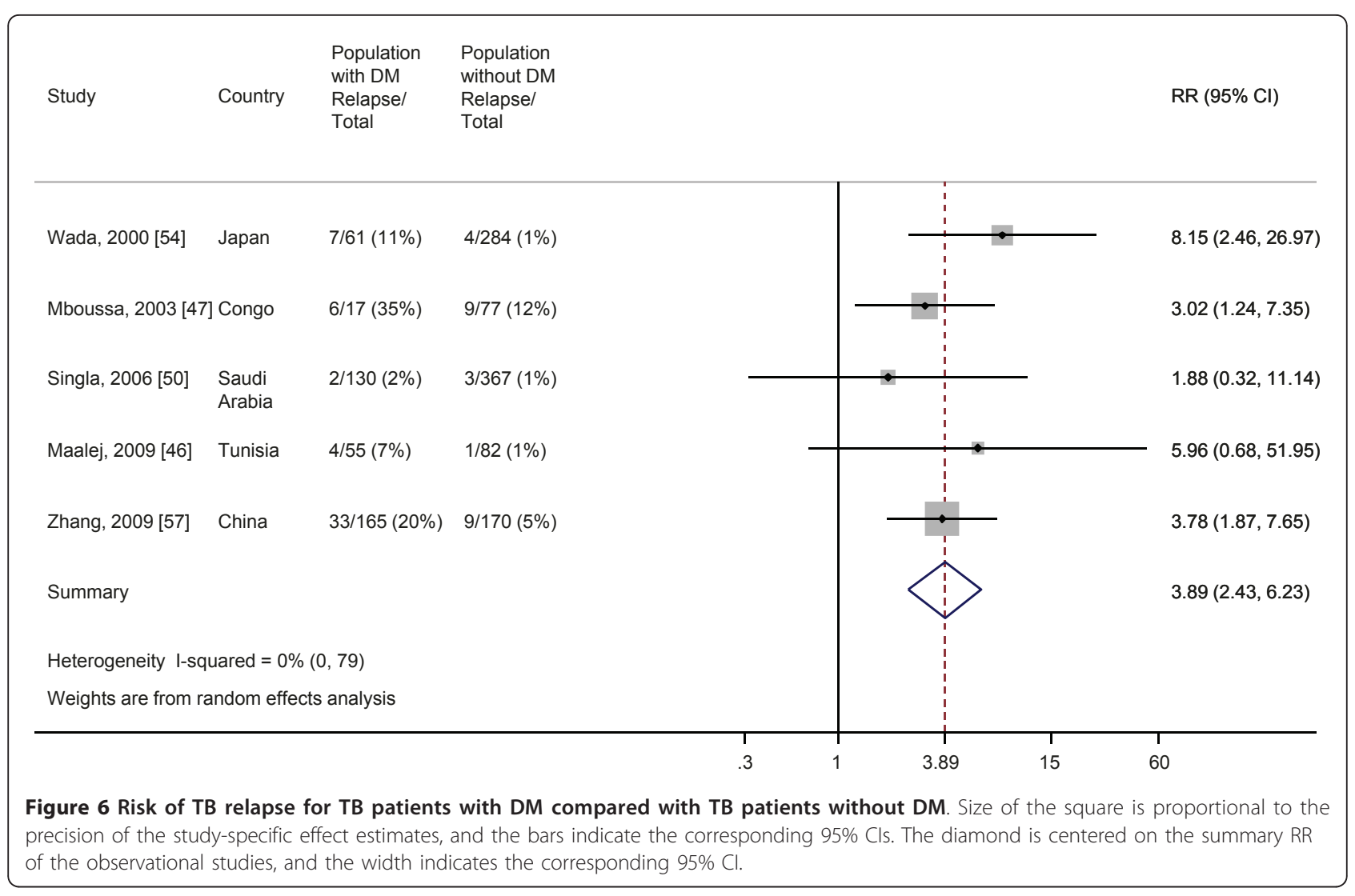

\begin{tabular}{|c|c|c|c|c|c|}
\hline Study & Country & $\begin{array}{l}\text { Population } \\
\text { with DM } \\
\text { DR Recurrent TB/ } \\
\text { Recurrent TB }\end{array}$ & $\begin{array}{l}\text { Population } \\
\text { without DM } \\
\text { DR Recurrent TB/ } \\
\text { Recurrent TB }\end{array}$ & & OR $(95 \% \mathrm{Cl})$ \\
\hline Wang, 2001 [55] & Taiwan & $3 / 25(12 \%)$ & $27 / 173(16 \%)$ & $\longrightarrow$ & $0.80(0.17,3.67)$ \\
\hline Subhash, 2003 [51] & India & $20 / 28(71 \%)$ & $106 / 145(73 \%)$ & & $0.92(0.37,2.27)$ \\
\hline Ito, 2004 [43] & Japan & $2 / 16(13 \%)$ & $16 / 93(17 \%)$ & & $0.69(0.14,3.37)$ \\
\hline Fisher-Hoch, $2008[39$ & 9] Mexico & $11 / 24(46 \%)$ & $14 / 64(22 \%)$ & & $3.00(1.10,8.19)$ \\
\hline Fisher-Hoch, $2008[39$ & 9] USA & $3 / 23(13 \%)$ & $6 / 51(12 \%)$ & + & $1.10(0.27,4.49)$ \\
\hline Summary & & & & & $1.24(0.72,2.16)$ \\
\hline \multicolumn{6}{|c|}{ Heterogeneity I-squared $=6 \%(0,80)$} \\
\hline \multicolumn{6}{|c|}{ Weights are from random effects analysis } \\
\hline & & & $\begin{array}{l} \\
.1\end{array}$ & $\begin{array}{lll} & & \\
1 & 1.24\end{array}$ & $\begin{array}{l}1 \\
10\end{array}$ \\
\hline
\end{tabular}


We expect that the risks of the combined outcome, failure and death, and death alone are underestimated due to loss to follow-up. The patients who default or are transferred out are not followed for the entire treatment period, and their final outcome is therefore not observed. In the one study that used survival analysis to adjust for this loss of follow-up, the HRs were higher than the pooled effect estimates in both the univariate and adjusted analyses [48]. Since the rate of death is higher among persons with DM than those without at baseline, the increased death rate may reflect that risk rather than indicate a higher rate of TB associated mortality among those with DM [59]. However, the differential age specific mortality experienced by persons with DM probably does not account for the odds ratio of death of almost 5 in the adjusted analysis.

Although we found evidence for publication bias in the analysis of the combined outcome, failure and death, and the unadjusted analysis of death when we used Egger's test, this was not confirmed with Begg's test, a method that is less susceptible to false positive results $[60,61]$, nor was it found in the analysis of death restricted to studies that adjusted for age and other confounders.

Patients with DM were four times more likely to develop a relapse of TB disease than patients without DM. Considering the fact that these individuals were considered cured or treatment complete, the patients could have relapsed through one of two possible routes: they may have been cured but experienced a recurrence of the former infection, or they may have been re-infected with a new strain of $\mathrm{TB}$. The increased risk of recurrent disease in either of these scenarios is consistent with prior evidence suggesting that those with DM are at increased risk of developing TB disease [3-6]. Furthermore, health facility exposure to $\mathrm{TB}$, an important contributor to the total TB infection risk in people living with HIV [62], may contribute to the risk of re-infection in patients with DM due to repeated attendance at health facilities for diabetes management.

The results in this systematic review may underestimate the risk of relapse, because patients with DM are more likely to die during a first course of TB therapy and in the time period prior to a diagnosis of relapse [63]. Thus, patients with DM may be less likely to have recurrent TB than patients without DM because of loss to competing risks. This methodological consideration suggests that the appropriate study design to assess relapse is survival analysis, and only one of the studies reported here used that approach [54]. Other limitations of this analysis included the small numbers of relapses that occurred and lack of adjustment for confounding factors.
We found no evidence that DM increased the risk of recurrent disease with $\mathrm{DR} T \mathrm{~TB}$, despite the greater risk for TB disease and impaired cell mediated immunity [64-68]. This finding is consistent with data from a recent pharmacological study that reported therapeutic levels of rifampicin, pyrazinamide and ethambutol in patients with DM who received standard dosing during the intensive phase of TB treatment [69]. However, if the effect of DM is relatively small, the four studies with only 208 cases of DR recurrent disease may not have had sufficient power to detect an association. Furthermore, these studies did not adjust for potential confounding factors such as HIV or frequency of medical care during TB treatment.

The increased risks of failure, death during TB treatment, and relapse among patients with DM are consistent with data from mouse models and human studies that show that DM impairs cell-mediated immunity [64-68]. Furthermore, a study by Restrepo et al. determines that poor diabetic control, as measured by glycosylated hemoglobin level, affects in vitro innate and type 1 cytokine responses [70]. We speculate that poor diabetes control, possibly exacerbated by TB disease, may be an important contributing factor to case fatality and relapse.

This study highlights the perils of using observational studies for a meta-analysis. Although meta-analyses of observational studies are frequently faulted for finding false statistically significant associations by combining small studies affected by confounding [71], we found evidence that an association may also be diminished by confounding or bias resulting from study design. Misclassification of the diagnosis of DM may have also diminished the association between DM and TB outcome. Since glucose levels are transiently increased in the setting of active TB [23,24], and the studies did not specify that the diagnosis of DM must precede that of $\mathrm{TB}$, some patients diagnosed with DM may have been experiencing only a transient episode of hyperglycemia. The systematic review highlights the need for large-scale prospective studies with appropriate study design, prospective diagnoses of diabetes, control for confounding factors, and clear TB outcomes to further clarify the strength of the associations.

\section{Conclusions}

This study reports that diabetes is associated with an increased risk of the combined endpoint of failure and death, death during TB treatment, and relapse. It is the first study that we are aware of that quantifies the associations based on a systematic review of the literature. The implications of the negative impact of DM on TB outcomes include poor individual outcomes, increased risk of secondary transmission, and increased incidence of TB 
disease. Considering the increasing burden of DM, particularly in areas with highly prevalent TB, TB control programs will need to expand efforts to focus on treatment and monitoring of patients with DM and TB disease.

\section{Additional material}

Additional file 1: Additional file 1.ppt. Begg's funnel plot with pseudo 95\% confidence limits for all studies with sputum cultures at two to three months.

Additional file 2: Additional file 2.ppt. Begg's funnel plot with pseudo $95 \%$ confidence limits for all studies with the combined outcome of failure and death.

Additional file 3: Additional file 3.ppt. Begg's funnel plot with pseudo 95\% confidence limits for all studies with the outcome of death.

Additional file 4: Additional file 4.ppt. Begg's funnel plot with pseudo 95\% confidence limits for all studies with the outcome of death adjusted for age and other confounding factors.

Additional file 5: Additional file 5.ppt. Begg's funnel plot with pseudo 95\% confidence limits for all studies with TB relapse.

Additional file 6: Additional file 6.ppt. Begg's funnel plot with pseudo 95\% confidence limits for all studies with recurrent TB that is DR.

\section{Abbreviations}

Cl: confidence interval; DM: diabetes mellitus; DR: drug-resistant; FBG: fasting blood glucose; HIV: human immunodeficiency virus; HR: hazard ratio: MOOSE: Meta-analysis of Observational Studies in Epidemiology; OR: odds ratio; RR: risk ratio; TB: tuberculosis; WHO: World Health Organization.

\section{Acknowledgements}

We thank Svetlana Dotsenko, Molly Franke, Federico Frigerio, Kosuke Kawai, and Wei Liu for their help in translating non-English articles. We also thank Bronwyn Murray-Bozeman, Caleb Murray-Bozeman, and Ursula Murray-Bozeman for their assistance in the computerized and manual literature search.

This systematic review was supported by a grant from the World Diabetes Foundation. Authors from Harvard University, the International Union Against Tuberculosis and Lung Disease, the World Diabetes Foundation, the World Health Organization, Columbia University, and Brown University contributed to the planning and execution of the systematic review.

\section{Author details}

'Division of Infectious Diseases, Massachusetts General Hospital, Boston, MA, USA. ${ }^{2}$ Department of Epidemiology, Harvard School of Public Health, Boston, MA, USA. ${ }^{3}$ International Union Against Tuberculosis and Lung Disease, Paris, France. ${ }^{4}$ London School of Hygiene and Tropical Medicine, Keppel Street, London, UK. ${ }^{5}$ Center for Infectious Disease Epidemiologic Research, Columbia University, New York, NY, USA. ${ }^{6}$ The Warren Alpert Medical School of Brown University, Providence, RI, USA. 'World Diabetes Foundation, Lyngby, Denmark. ${ }^{8}$ Stop-TB Department, World Health Organization, Geneva, Switzerland. 'Division of Global Health Equity, Brigham \& Women's Hospital, Boston, MA, USA. ${ }^{10}$ Department of Epidemiology, Harvard School of Public Health, Boston, MA, USA.

\section{Authors' contributions}

MB participated in the design, literature search, analysis and drafting of the manuscript. AH participated in the conception, design, analysis and drafting of the manuscript. CJ participated in the design, data extraction and analysis. $\mathrm{JH}$ participated in the literature search and data extraction. AK, KL and SO conceived of the study and participated in the writing of the manuscript. SG participated in the literature search and data extraction. MM participated in the design, analysis, and drafting of the manuscript. All authors read and approved the final manuscript.

\section{Competing interests}

The authors declare that they have no competing interests.
Received: 3 May 2011 Accepted: 1 July 2011 Published: 1 July 2011

\section{References}

1. Lonnroth K, Raviglione M: Global epidemiology of tuberculosis: prospects for control. Semin Respir Crit Care Med 2008, 29:481-491.

2. World Heath Organization: Global tuberculosis control 2009: epidemiology, strategy, financing. Geneva, Switzerland; 2010 [http://www. who.int/tb/publications/global_report/2009/en], WHO/HTM/TB/2009.411.

3. Ponce-De-Leon A, Garcia-Garcia Md Mde L, Garcia-Sancho MC, GomezPerez FJ, Valdespino-Gomez JL, Olaiz-Fernandez G, Rojas R, Ferreyra-Reyes L, Cano-Arellano B, Bobadilla M, Small PM, Sifuentes-Osornio J: Tuberculosis and diabetes in southern Mexico. Diabetes Care 2004, 27:1584-1590.

4. Jeon CY, Murray MB: Diabetes mellitus increases the risk of active tuberculosis: a systematic review of 13 observational studies. PLOS Med 2008, 5:e152.

5. Stevenson CR, Forouhi NG, Roglic G, Williams BG, Lauer JA, Dye C, Unwin N: Diabetes and tuberculosis: the impact of the diabetes epidemic on tuberculosis incidence. BMC Public Health 2007, 7:234.

6. Kim SJ, Hong YP, Lew WJ, Yang SC, Lee EG: Incidence of pulmonary tuberculosis among diabetics. Tuber Lung Dis 1995, 76:529-533.

7. Dooley KE, Chaisson RE: Tuberculosis and diabetes mellitus: convergence of two epidemics. Lancet Infect Dis 2009, 9:737-746.

8. International Diabetes Federation: Diabetes Factsand Figures 2009. Diabetes Prevalence. 2009 [http://www.idf.org/diabetes-prevalence].

9. Restrepo BI: Convergence of the tuberculosis and diabetes epidemics: renewal of old acquaintances. Clin Infect Dis 2007, 45:436-438.

10. Restrepo BI, Fisher-Hoch SP, Crespo JG, Whitney E, Perez A, Smith B, McCormick JB, Nuevo Santander Tuberculosis Trackers: Type 2 diabetes and tuberculosis in a dynamic bi-national border population. Epidemiol Infect 2007, 135:483-491.

11. Alisjahbana B, Sahiratmadja E, Nelwan EJ, Purwa AM, Ahmad Y, Ottenhoff TH, Nelwan RH, Parwati I, van der Meer JW, van Crevel R: The effect of type 2 diabetes mellitus on the presentation and treatment response of pulmonary tuberculosis. Clin Infect Dis 2007, 45:428-435.

12. Dooley KE, Tang T, Golub JE, Dorman SE, Cronin W: Impact of diabetes mellitus on treatment outcomes of patients with active tuberculosis. Am J Trop Med Hyg 2009, 80:634-639.

13. Stroup DF, Berlin JA, Morton SC, Olkin I, Williamson GD, Rennie D, Moher D, Becker BJ, Sipe TA, Thacker SB: Meta-analysis of observational studies in epidemiology: a proposal for reporting. Meta-analysis Of Observational Studies in Epidemiology (MOOSE) group. JAMA 2000, 283:2008-2012.

14. World Health Organization: Treatment of tuberculosis. Guidelines for National Programmmes. Geneva, Switzerland; 2010 [http://whqlibdoc.who. int/hq/2003/WHO_CDS_TB_2003.313_eng.pdf], WHO/CDS/TB 2003.313.

15. World Health Organization: Treatment of tuberculosis guidelines fourth edition. Geneva, Switzerland; 2010 [http://whqlibdoc.who.int/publications/ 2010/9789241547833_eng.pdf], WHO/HTM/TB/2009.402.

16. World Health Organization, International Union Against Tuberculosis and Lung Disease, Royal Netherlands Tuberculosis Association: Revised international definitions in tuberculosis control. Int I Tuberc Lung Dis 2001, 5:213-215.

17. World Health Organization: Definition and diagnosis of diabetes mellitus and intermediate hyperglycemia. Geneva, Switzerland: WHO; 2010 [http:// www.who.int/diabetes/publications/Definition\%20and\%20diagnosis\%20of\% 20diabetes_new.pdf].

18. The Expert Committee on the Diagnosis and Classification of Diabetes Mellitus: Report of the Expert Committee on the Diagnosis and Classification of Diabetes Mellitus. Diabetes Care 1997, 20:1183-1197.

19. Greenland S: Quantitative methods in the review of epidemiologic literature. Epidemiol Rev 1987, 9:1-30.

20. Cochran WG: The combination of estimates from different experiments. Biometrics 1954, 10:101-129.

21. Higgins JP, Thompson SG: Quantifying heterogeneity in a meta-analysis. Stat Med 2002, 21:1539-1558

22. DerSimonian R, Laird N: Meta-analysis in clinical trials. Control Clin Trials 1986, 7:177-188.

23. Jeon CY, Harries AD, Baker MA, Hart JE, Kapur A, Lönnroth K, Ottmani SE, Goonesekera S, Murray MB: Bi-directional screening for tuberculosis and diabetes: a systematic review. Trop Med Int Health 2010, 15:1300-1314.

24. Oluboyo PO, Erasmus RT: The significance of glucose intolerance in pulmonary tuberculosis. Tubercle 1990, 71:135-138. 
25. Begg $C B$, Mazumdar $M$ : Operating characteristics of a rank correlation test for publication bias. Biometrics 1994, 50:1088-1101.

26. Egger M, Davey Smith G, Schneider M, Minder C: Bias in meta-analysis detected by a simple, graphical test. BMJ 1997, 315:629-634.

27. StataCorp. Stata: Statistical Software: Release 10. College Station (Texas): StataCorp LP 2007.

28. Ambrosetti M, Besozzi G, Codecasa LR, Farris B, Nutini S, Saini L, Casali L, Nardini S, Migliori GB: The Italian AIPO study on tuberculosis treatment results, report 1995 National AIPO "Tuberculosis" Study Group. Monaldi Arch Chest Dis 1999, 54:49-54.

29. Ambrosetti M, Besozzi G, Farris B, Nutini S, Saini L, Casali L, Pretto P, Orani G, Calabro S, Migliori GB: The Italian AIPO study on tuberculosis treatment results, report 1996. National AIPO "Tuberculosis" Study Group. Associazione Italiana Pneumologi Ospedalieri. Monaldi Arch Chest Dis 1999, 54:237-241.

30. Ambrosetti M, Besozzi G, Codecasa LR, Farris B, Nutini S, Saini L, Casali L Nardini S, Migliori GB: The Italian AIPO study on tuberculosis treatment results, report 1997. National AIPO "Tuberculosis" Study Group. Monaldi Arch Chest Dis 1999, 54:407-412.

31. Anunnatsiri S, Chetchotisakd P, Wanke C: Factors associated with treatment outcomes in pulmonary tuberculosis in Northeastern Thailand. Southeast Asian J Trop Med Public Health 2005, 36:324-330

32. Banu Rekha W, Balasubramanian $R$, Swaminathan $S$, Ramachandran $R$, Rahman F, Sundaram V, Thyagarajan K, Selvakumar N, Adhilakshmi AR, lliayas S, Narayanan PR: Sputum conversion at the end of intensive phase of Category-1 regimen in the treatment of pulmonary tuberculosis patients with diabetes mellitus or HIV infection: An analysis of risk factors. Indian J Med Res 2007, 126:452-458.

33. Bashar M, Alcabes P, Rom WN, Condos R: Increased incidence of multidrug-resistant tuberculosis in diabetic patients on the Bellevue Chest Service, 1987 to 1997. Chest 2001, 120:1514-1519.

34. Blanco JAG, Toste IS, Fernandez ML, Morales RG, Alvarez RF, Cuadrado GR, Gonzalvez AM, Martin IJG: Tobacco smoking and sputum smear conversion in pulmonary tuberculosis. Medicina Clinica 2007, 128:565-568.

35. Centis R, lanni A, Migliori GB: Evaluation of tuberculosis treatment results in Italy, report 1998. Tuberculosis section of the National AIPO Study Group on Infectious Disease and the SMIRA Group. Monaldi Arch Chest Dis 2000, 55:293-298

36. Centis R, Migliori GB: Evaluation of tuberculosis treatment results in Italy, report 1999. Monaldi Arch Chest Dis 2002, 57:297-305.

37. Chiang CY, Lee JJ, Yu MC, Enarson DA, Lin TP, Luh KT: Tuberculosis outcomes in Taipei: factors associated with treatment interruption for 2 months and death. Int I Tuberc Lung Dis 2009, 13:105-111.

38. Fielder JF, Chaulk CP, Dalvi M, Gachuhi R, Comstock GW, Sterling TR: A high tuberculosis case-fatality rate in a setting of effective tuberculosis control: implications for acceptable treatment success rates. Int I Tuberc Lung Dis 2002, 6:1114-1117.

39. Fisher-Hoch SP, Whitney E, McCormick JB, Crespo G, Smith B, Rahbar MH, Restrepo BI, Nuevo Santander Tuberculosis Trackers: Type 2 diabetes and multidrug-resistant tuberculosis. Scand I Infect Dis 2008, 40:888-893.

40. Guler M, Unsal E, Dursun B, Aydln O, Capan N: Factors influencing sputum smear and culture conversion time among patients with new case pulmonary tuberculosis. Int I Clin Pract 2007, 61:231-235.

41. Hara H: From the aspects of complicated diseases. Kekkaku 1996, 71:47-56.

42. Hasibi M, Rasoulinejad M, Hosseini SM, Davari P, Sahebian A, Khashayar P: Epidemiological, clinical, laboratory findings, and outcomes of disseminated tuberculosis in Tehran, Iran. South Med J 2008, 101:910-913.

43. Ito K, Wada M, Yoshiyama T, Ohmori M, Ogata H: Drug resistance in recurrent cases of tuberculosis. Kekkaku 2004, 79:461-467.

44. Kitahara Y, Ikeda A, Kajiki A, Maruyama M, Harada S, Harada Y, Takamoto M, Ishibashi T: An investigation on risk factors relating to the treatment difficulty in originally treated pulmonary tuberculosis cases. Kekkaku 1994, 69:503-511.

45. Kourbatova EV, Borodulin BE, Borodulina EA, del Rio C, Blumberg HM, Leonard MK Jr: Risk factors for mortality among adult patients with newly diagnosed tuberculosis in Samara, Russia. Int I Tuberc Lung Dis 2006, 10:1224-1230.

46. Maalej S, Belhaoui N, Bourguiba M, Mahouachi R, Chtourou A, Taktak S, Fennira H, Slim L, Kheder AB, Drira I: Pulmonary tuberculosis and diabetes. A retrospective study of 60 patients in Tunisia. Presse Med 2009, 38:20-24.
47. Mboussa J, Monabeka H, Kombo M, Yokolo D, Yoka-Mbio A, Yala F: Course of pulmonary tuberculosis in diabetics. Rev Pneumol Clin 2003, 59:39-44.

48. Oursler KK, Moore RD, Bishai WR, Harrington SM, Pope DS, Chaisson RE: Survival of patients with pulmonary tuberculosis: clinical and molecular epidemiologic factors. Clin Infect Dis 2002, 34:752-759.

49. Pina JM, Dominguez A, Alcaide J, Alvarez J, Camps N, Diez M, Godoy P, Jansá JM, Minquell S, Arias C: Excess mortality due to tuberculosis and factors associated to death in and annual cohort of patients diagnosed of tuberculosis. Rev Clin Esp 2006, 206:560-565.

50. Singla R, Khan N, Al-Sharif N, Ai-Sayegh MO, Shaikh MA, Osman MM: Influence of diabetes on manifestations and treatment outcome of pulmonary TB patients. Int J Tuberc Lung Dis 2006, 10:74-79.

51. Subhash HS, Ashwin I, Mukundan U, Danda D, John G, Cherian AM, Thomas K: Drug resistant tuberculosis in diabetes mellitus: a retrospective study from south India. Trop Doct 2003, 33:154-156.

52. Tatar D, Senol G, Alptekin S, Karakurum C, Aydin M, Coskunol I: Tuberculosis in diabetics: Features in an endemic area. Jpn J Infect Dis 62:423-427.

53. Vasankari T, Holmstrom P, Ollgren J, Liippo K, Kokki M, Ruutu P: Risk factors for poor tuberculosis treatment outcome in Finland: a cohort study. BMC Public Health 2007, 7:291.

54. Wada M: The effectiveness of pyrazinamide-containing six-month short course chemotherapy. Kekkaku 2000, 75:665-673.

55. Wang PD, Lin RS: Drug-resistant tuberculosis in Taipei, 1996-1999. Am J Infect Control 2001, 29:41-47.

56. Wang CS, Yang CJ, Chen HC, Chuang SH, Chong IW, Hwang JJ, Huang MS: Impact of type 2 diabetes on manifestations and treatment outcome of pulmonary tuberculosis. Epidemiol Infect 2009, 137:203-210.

57. Zhang $\mathrm{Q}$, Xiao H, Sugawara I: Tuberculosis complicated by diabetes mellitus at Shanghai Pulmonary Hospital, China. Jpn J Infect Dis 62:390-391.

58. World Heath Organization: Global tuberculosis control: a short update to the 2009 report. Geneva, Switzerland; 2010 [http://www.who.int/tb/ country/data/download/en/index.html].

59. Saydah SH, Eberhardt MS, Loria CM, Brancati FL: Age and the burden of death attributable to diabetes in the United States. Am J Epidemiol 2002, 156:714-719.

60. Peters $J$, Sutton AJ, Jones DR, Abrams KR, Rushton L: Comparison of two methods to detect publication bias in meta-analysis. JAMA 2006, 295:676-680

61. Sterne JAC, Gavaghan D, Egger M: Publication and related bias in metaanalysis: Power of statistical tests and prevalence in the literature. J Clin Epidemiol 2000, 53:1119-1129.

62. Bock NN, Jensen PA, Miller B, Nardell E: Tuberculosis infection control in resource-limited settings in the era of expanding HIV care and treatment. J Infect Dis 2007, 196:S108-113.

63. Gregg EW, Gu Q, Cheng YJ, Venkat Narayan KM, Cowie CC: Mortality trends in men and women with diabetes, 1971 to 2000. Ann Intern Med 2007, 147:149-155.

64. Saiki O, Negoro S, Tsuyuguchi I, Yamamura Y: Depressed immunological defense mechanisms in mice with experimentally induced diabetes. Infect Immun 1980, 28:127-131.

65. Yamashiro S, Kawakami K, Uezu K, Kinjo T, Miyagi K, Nakamura K, Saito A: Lower expression of Th1-related cytokines and inducible nitric oxide synthase in mice with streptozotocin-induced diabetes mellitus infected with Mycobacterium tuberculosis. Clin Exp Immunol 2005, 139:57-64.

66. Tsukaguchi K, Okamura H, Ikuno M, Kobayashi A, Fukuoka A, Takenaka H, Yamamoto C, Tokuyama T, Okamoto Y, Fu A, Yoshikawa M, Yoneda T, Narita N: The relation between diabetes mellitus and IFN-gamma, IL-12 and IL-10 productions by CD4+ alpha beta T cells and monocytes in patients with pulmonary tuberculosis. Kekkaku 1997, 72:617-622.

67. Al-Attiyah RJ, Mustafa AS: Mycobacterial antigen-induced Thelper type 1 (Th1) and Th2 reactivity of peripheral blood mononuclear cells from diabetic and non-diabetic tuberculosis patients and Mycobacterium bovis bacilli Calmette-Guerin (BCG)-vaccinated healthy subjects. Clin Exp Immunol 2009, 158:64-73.

68. Stalenhoef JE, Alisjahbana B, Nelwan EJ, van der Ven-Jongekrijg , Ottenhoff THM, van der Meer JWM, Nelwan RH, Netea MG, van Crevel R: The role of interferon-gamma in the increased tuberculosis risk in type 2 diabetes mellitus. Eur J Clin Microbiol Infect Dis 2008, 27:97-103. 
69. Ruslami R, Nijland HM, Adhiarta IG, Kariadi SH, Alisjahbana B, Aarnoutse RE, van Crevel R: Pharmacokinetics of antituberculosis drugs in pulmonary tuberculosis patients with type 2 diabetes. Antimicrob Agents Chemother 2010, 54:1068-1074.

70. Restrepo BI, Fisher-Hoch SP, Pino PA, Salinas A, Rahbar MH, Mora F, CortesPenfield N, McCormick JB: Tuberculosis in poorly controlled type 2 diabetes: altered cytokine expression in peripheral white blood cells. Clin Infect Dis 2008, 47:634-641.

71. Shapiro S: Is meta-analysis a valid approach to the evaluation of small effects in observational studies? J Clin Epidemiol 1997, 50:223-229.

\section{Pre-publication history}

The pre-publication history for this paper can be accessed here: http://www.biomedcentral.com/1741-7015/9/81/prepub

Cite this article as: Baker et al:: The impact of diabetes on tuberculosis treatment outcomes: A systematic review. BMC Medicine 2011 9:81.

\section{Submit your next manuscript to BioMed Central} and take full advantage of:

- Convenient online submission

- Thorough peer review

- No space constraints or color figure charges

- Immediate publication on acceptance

- Inclusion in PubMed, CAS, Scopus and Google Scholar

- Research which is freely available for redistribution

Submit your manuscript at www.biomedcentral.com/submit 